Pain Physician. 2003;6:527-535, ISSN 1533-3159

\title{
DeVelopment OF InTERdisciplinaRY SPINAL Interventional Pain Centers
}

\author{
Marcy T. Rogers, M Ed
}

The lifetime prevalence of spinal pain has been reported as $65 \%$ to $80 \%$ in the neck and low back. In the US each year, 500,000 $-1,000,000$ spine surgeries and 2 to 5 million interventional procedures are estimated to be performed. The burden created by chronic pain is enormous on the patient and society. Thus, the somatic, psychological, and physical manifestations of pain must be addressed in the overall assessment and treatment of these patients.

In a Gallup Survey of "Pain in America" more than 4 out of 10 adults (42\%) reported they experienced pain on a daily basis. Pain and pain syndromes originating in and involving the spine are common. The lifetime prevalence of spinal pain has been reported as $65 \%$ to $80 \%$ in the neck and low back (1-9).

The burden created by spinal pain is enormous extending beyond the patient's physical, emotional, social and financial impact. Demand continues to increase high quality, cost-effective, evidencebased methods for medical or conservative management of spinal conditions.

A myriad of treatment options exist for patients in pain, however, the best options for rehabilitation are rendered under the umbrella of an integrated delivery system involving a variety of specialists. An interventional pain center must offer services that have documented clinical efficacy with minimal risk, documented by outcomes that demonstrate improved quality of care, patient access, efficiency, effectiveness, and cost containment by improving the cost to benefit ratio.

Chronic spinal pain is considered as a multifactorial disorder. Modern diagnos-

From Management Technology Resources, San Diego, CA. Address Correspondence: Marcy T. Rog. ers, M Ed, 8910 University Center Lane, \#270, San Diego CA 92122.

E-mail: marcyrogers@mtr-apm.com

Funding: There was no external funding in preparation of this manuscript.
A myriad of treatment options exist for patients in pain however, with none of the modalities providing conclusive evidence in their effectiveness. The optimal course of care requires an integrated delivery system involving a variety of specialists. Due to the complexities of diagnosis and management, patients are best managed utilizing a multidisciplinary approach under an umbrella of services offered by a spinal diagnostic and interdisciplinary pain center.
This review identifies various pain syndromes and conditions and provides a model for the establishment of an interdisciplinary pain center as well as the resources, guidelines, and infrastructure required for operating a successful pain center in any setting; free-standing, hospital-based, or academic.

Keywords: Spinal diagnostic pain center, multidisciplinary care, economic impact, disability, interventional techniques, strategic planning tic techniques, including interventional techniques, are able to demonstrate a structural basis in at least $50 \%$ and as high as $90 \%$ of patients (9). Even then, due to the complexities of diagnosis and management, patients are best managed utilizing a comprehensive multidisciplinary approach under the umbrella of services offered by a spinal interventional pain center. This review summarizes the planning, benefits, infrastructure, and resources required to establish an interventional pain center. In addition, an outline of guidelines for managing, marketing, and operating a successful interventional pain center is provided whether it is free-standing, hospital-based, or an institutional facility.

\section{Impact of Chronic Pain}

More than 40 million people in the United States are affected with musculoskeletal pain. In the United States each year, 500,000 - 1,000,000 spine surgeries and 2 to 5 million interventional procedures are estimated to be performed (9).

Over 400 million workdays are lost each year. In the United States, the number of persons reporting disabling conditions increased from 49 million during 1991 to 1992 to 54 million during 1994 to 1995 (10). Spine and musculoskeletal disorders account for nearly 70 million physician office visits in the United States each year, and an estimated 130 million outpatient, hospital and emergency room visits. In 1999, nearly 1 million people took time away from work to be treated and recover from work-related musculoskeletal pain or impairment of function in the lower back or upper extremities. Conservative estimates of the economic burden imposed by these disorders, as measured by compensation costs, lost wages and lost productivity, are between $\$ 45$ and $\$ 54$ billion annually. Moreover, statistics reveal that a person who remains out of the work force for up to six months due to a back injury has less than a 50\% probability rate of ever returning to work; after twelve months, the rate drops to less than $12 \%$; and after two or more years, the rate decreases to less than $1 \%$. It has also been found that in a large percentage of persons who have undergone multiple surgeries, performed by one or more spine surgeons, there is a greater degree of Failed Back Surgery Syndrome and longterm disability. This particular diagnosis prevails as the leading condition for workrelated injuries (11).

During 1996, direct medical costs for persons with disabilities were $\$ 260$ billion (12, 13). A 1999 US report of prevalence or disabilities and associated health conditions among adults reported 44 million of $22 \%$ of the adults as having a disability (14). The cost of medical care for a disabled older person averages 3 times that for a non-disabled senior (15). Of the total percentage of disabilities, $63 \%$ oc- 
curred among working adults; of these 27.8 million $(16.5 \%)$ had a disability and 17.7 million $(10.5 \%)$ had a limitation in their ability to work at a job or business. Of all the adults with disabilities, $17.5 \%$ had arthritis and rheumatism, $16.5 \%$ had back or spine problems, and only $7 \%$ had cardiac or vascular problems (9).

The majority of costs caused by chronic pain are due to disability compensation, reduced productivity, and lost tax revenue. The annual health care cost incurred by a chronic pain patient, excluding fees for surgical procedures, may range from $\$ 500$ to as high as $\$ 35,400$, with the average ranging from $\$ 12,900$ to $\$ 18,833$ annually (16-19).

Further, contrary to popular belief, the vast majority of chronic pain patients are managed with medication. For example in 1999, more than 3 million prescriptions were written for OxyContin ${ }^{\circledR}$ (19) whose cost alone would exceed $\$ 4,500$ per year, not including related physician visits for laboratory work (20). Further, there has been growing support for the use of other prescriptive preparations including anti-convulsants, anti-depressants, and topical preparations for neuropathic pain syndromes $(19,21)$.

\section{INTERDISCIPLINARY SPINE CenteR}

\section{Rationale}

The burden created by spinal pain and societal impact extends beyond the patient's physical, emotional, and financial suffering. Employers continue to demand cost-effective, alternative, innovative, and effective methods for management of spinal conditions due to the soaring costs of managing work-related injuries, particularly those involving the musculoskeletal sysyem.

Chronic spinal pain is a multifactorial disorder with many possible etiologies. The biopsychosocial model, which emerged in the 1980s, viewed chronic spinal pain as a biopsychosocial phenomenon, in which biological, psychological, and social factors dynamically interact with each other. The biopsychosocial model described here includes the bio part also along with the psychosocial and functional approaches. Modern technology, including magnetic resonance imaging (MRI), computed tomographic axial scanning (CT), neurophysiologic testing, and comprehensive physical examination with psychological evaluation, can identify the cause of low back pain in only $15 \%$ of patients in the absence of disc herniation and neurological deficit. Further, overall inaccurate or incomplete diagnosis in patients referred to pain treatment centers has been described as ranging from $40 \%$ to $67 \%$, and the incidence of psychogenic pain has been shown to be present only in 1 of 3,000 patients, with the presence of pain of organic origin mistakenly branded as psychosomatic in $98 \%$ of the cases (9). It has been identified that facet joints, intervertebral discs, ligaments, fascia, muscles, and nerve root dura are the tissues capable of transmitting pain in the low back. Using appropriate interventional techniques, a structural diagnosis may be established in $50 \%$ or as many as $80 \%$ of the patients suffering with chronic spinal pain in conjunction with other diagnostic techniques.

Interventional techniques include diagnostic, as well as therapeutic. The rationale has been established for facet joint blocks, discography, transforaminal epidural injections, and sacroiliac joint injections in the diagnosis of spinal pain. The rationale is based on the facts that these structures have nerve supply, the structures are capable of causing pain similar to that seen clinically in normal volunteers, the structures are susceptible to disease and/or injuries that are known to be painful, and, these structures have been shown to be a source of pain in patients, using diagnostic techniques of known reliability and validity (9).

On the basis of developments in interventional pain management, with precision diagnostic techniques, a structural cause of pain may be identified in $70 \%$ to $80 \%$ of the patients with chronic spinal pain. In patients without neurological symptoms, disc herniation, and positive nerve conduction studies, diagnostic interventional techniques have shown that facet joints are the source of chronic spinal pain in $15 \%$ to $45 \%$ of the heterogeneous groups of patients with chronic low back pain, $48 \%$ of the patients with thoracic pain, and $54 \%$ to $67 \%$ of the patients with chronic neck pain, utilizing controlled local anesthetic blocks, incorporating IASP criteria; internal disc disruption in 39\% of the patients suffering with chronic low back pain, and primary discogenic pain in $26 \%$ of patients suffering with chronic low back pain demonstrated by provocative discography following IASP criteria; and sacroiliac joint pain with controlled local anesthetic blocks in as low as $2 \%$ and as high as $30 \%$ of the patients (9).

The rationale for therapeutic interventional techniques in the spine is based upon several considerations. First, cardinal source(s) of chronic spinal pain, namely discs and joints, are accessible to neural blockade. Second, removal or correction of structural abnormalities of the spine may fail to cure and may even worsen painful conditions. Third, degenerative process of the spine and origin of spinal pain are complex. Fourth, the effectiveness of a large variety of therapeutic interventions in managing chronic spinal pain has not been demonstrated conclusively.

Interventional techniques in the management of chronic spinal pain include neural blockade and minimally invasive surgical procedures ranging from epidural injections, facet joint injections, and neuroablation techniques, to intradiscal thermal therapy, disc decompression, morphine pump implantation, and spinal cord stimulation.

\section{Definition of Multidisciplinary Care}

Under a multidisciplinary care model, patients are evaluated by specialty-trained interventional pain specialists and ancillary providers. The terms multidisciplinary or comprehensive elicit significant confusion. The terms relate to a pain physician's primary specialty. Thus, an interventionalist perceives a multidisciplinary or comprehensive program as the one with interventional techniques as the primary modality with physical and psychological modalities as secondary components. In contrast, a psychiatrist, rehabilitation specialist, or a surgeon might tend to emphasize psychology/psychiatry, physical therapy/ functional rehabilitation and surgery, with multidisciplinary management achieved by secondary application of other modalities such as interventional techniques. For purposes of this review, multidisciplinary care is provided in an interventional pain management setting. The National Uniform Claim Committee (NUCC) and the American Society of Interventional Pain Physicians (ASIPP) define interventional pain management as: 
"The discipline of medicine devoted to the diagnosis and treatment of pain and related disorders with the application of interventional techniques in managing subacute, chronic, persistent, and intractable pain, independently or in conjunction with other modalities of treatments."

\section{Benefits}

In the multidisciplinary care model, well-defined clinical algorithms and guidelines are used to ensure standardization of care. Rigid documentation and outcomes analyses are performed to substantiate treatment decisions and demonstrate superior effectiveness to payers, claims administrators, and employers. A practice continuum is used where patients must demonstrate failure at each level of care, beginning with conservative modalities, in order to progress to the next level of intervention. Ongoing patient satisfaction surveys are performed during the entire process and for a period of up to two years post- surgery or care. Clinical and administrative management is orchestrated to increase efficiency, coordinate care delivery, and improve timely reporting to claims managers and adjusters.

Non-operative and operative modalities are employed in the delivery of patient care and may include: Therapeutic and diagnostic interventional injections, implantable devices, radio frequency lesioning, intradiscal electrocoagulation, state-of-the-art materials and devices, functional restoration, and behavioral medicine.

A multidisciplinary system of care offers an innovative, cost-effective, and comprehensive approach for the treatment of malignant and non-malignant pain. Further, it provides a coordinated interaction of interventional pain techniques and other modalities. A diseasebased model is utilized to provide global management of the disease or injury, spanning from diagnosis to return to function. Other benefits include: An organized, coordinated approach to diagnosis and treatment; specialty-focused, outcome driven care with well-defined critical pathways; decreased utilization of medical services and medications; increased patient satisfaction; reduced cost of care and disability; quicker return to work; and decreased length of treatment (Figs. 1-4).

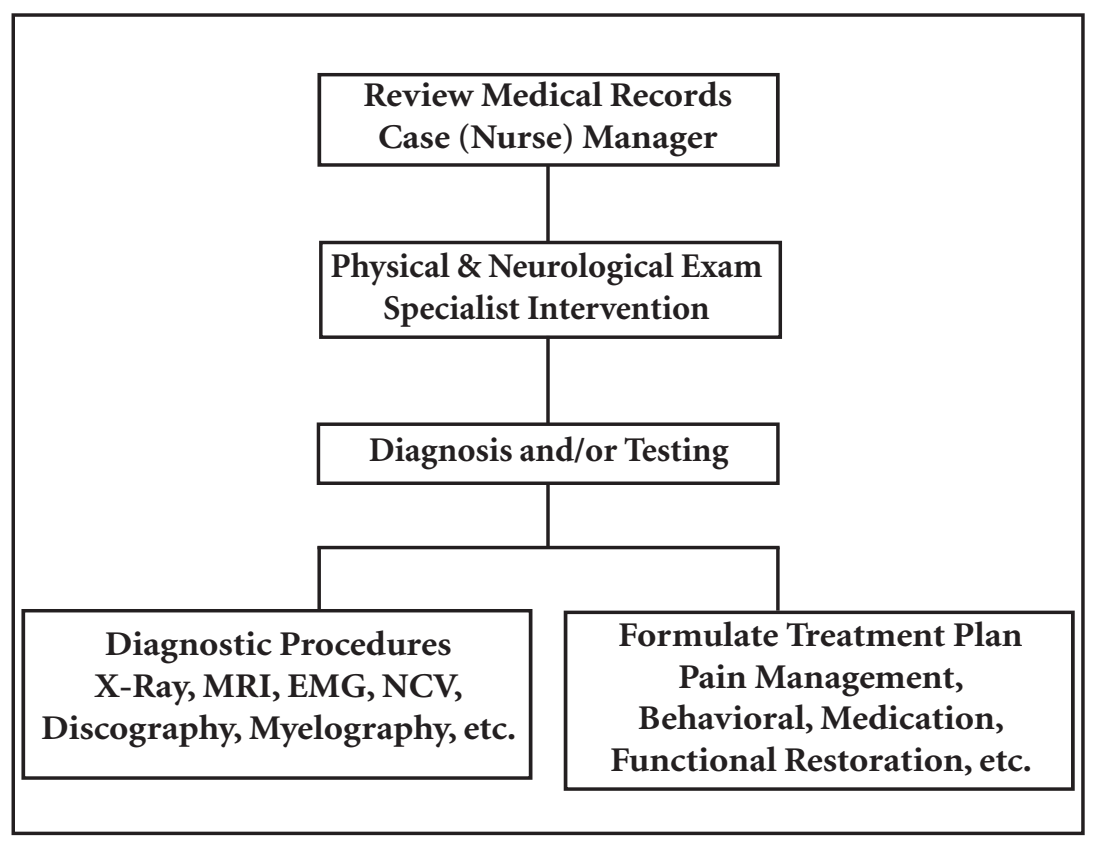

Fig 1. Referral to Pain Center

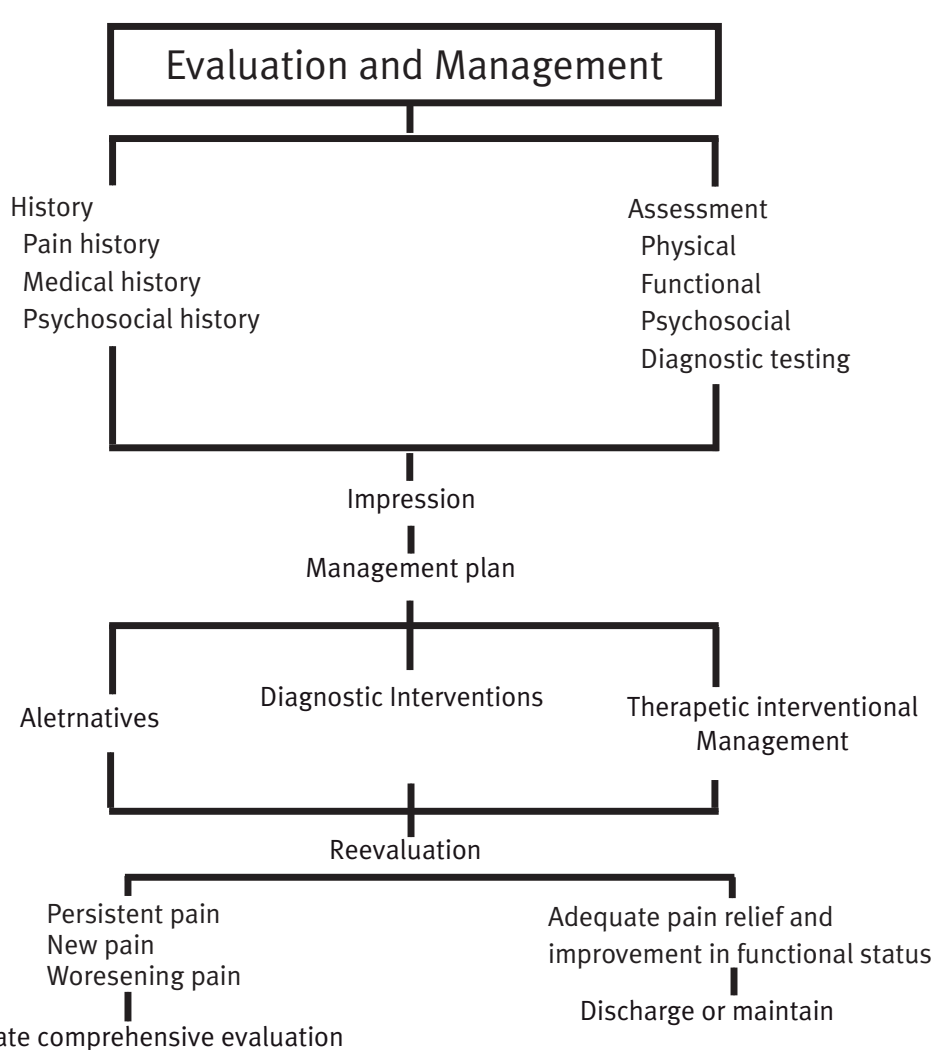

Adapted from ref. (9)

Fig 2. Suggested algorithm for comprehensive evaluation and management of chronic pain 


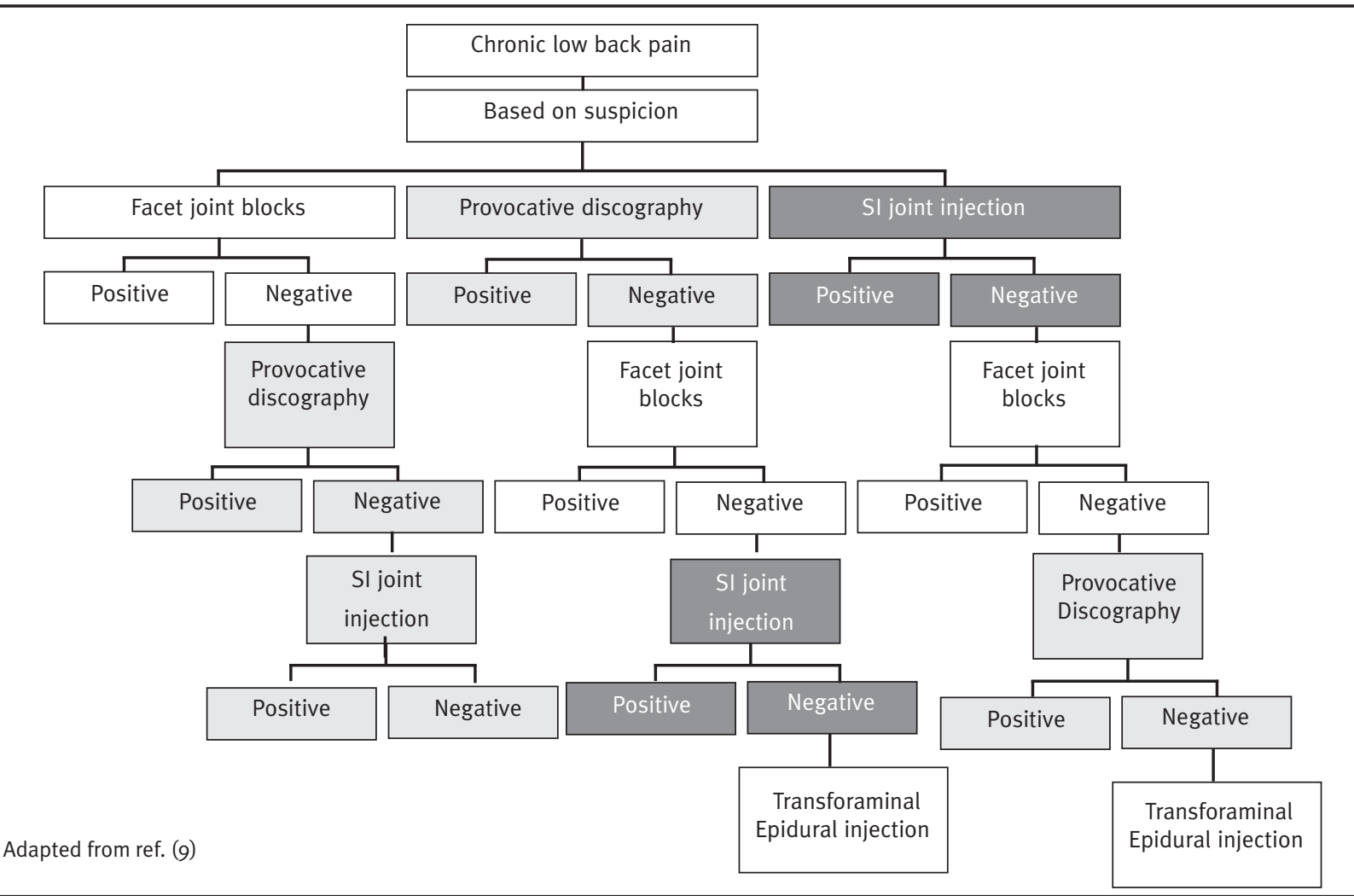

Fig 3. An algorithmic approach to diagnosis of chronic low back pain without disc herniation

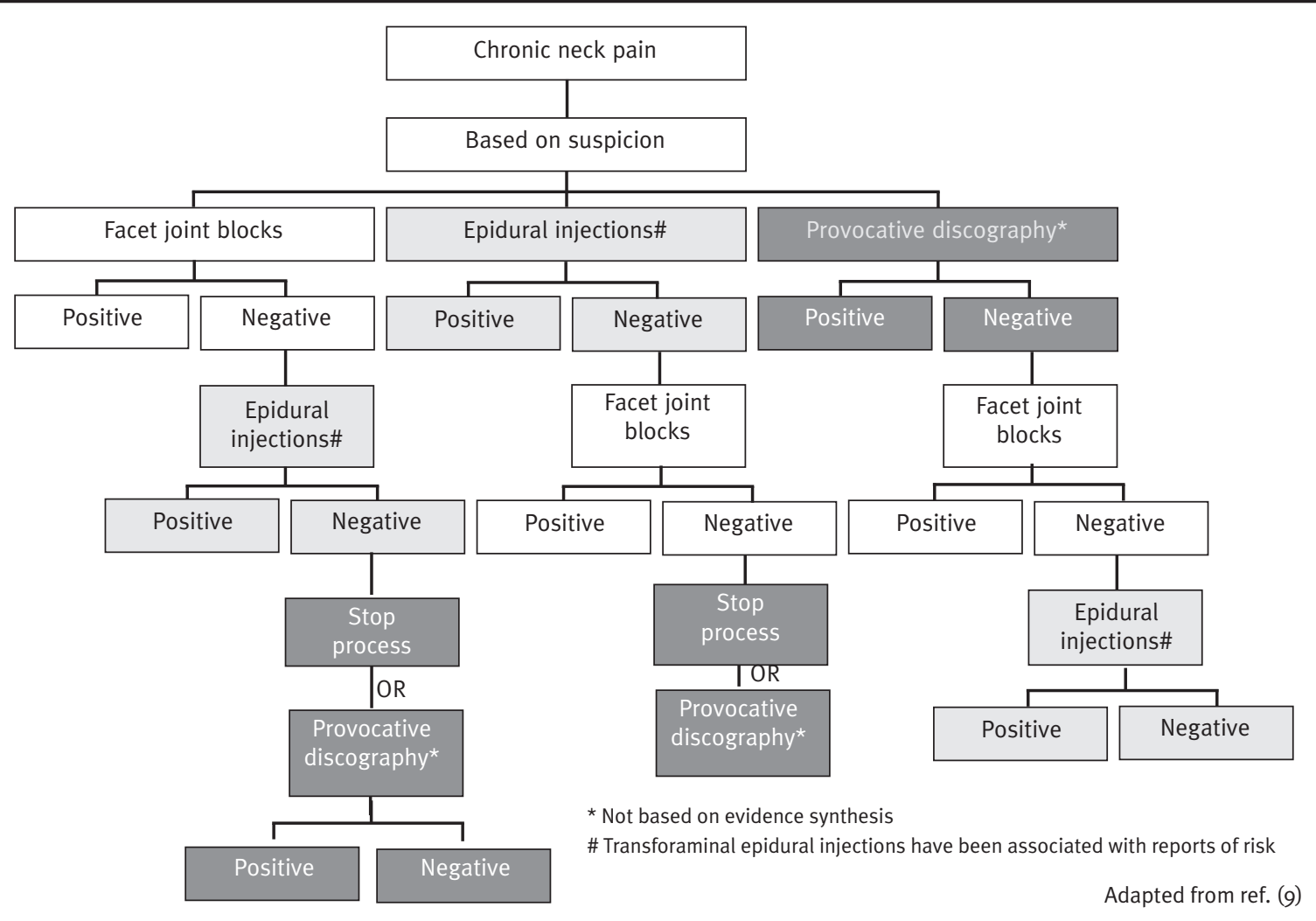

Fig 4. An algorithmic approach to diagnosis of chronic neck pain without disc herniation 


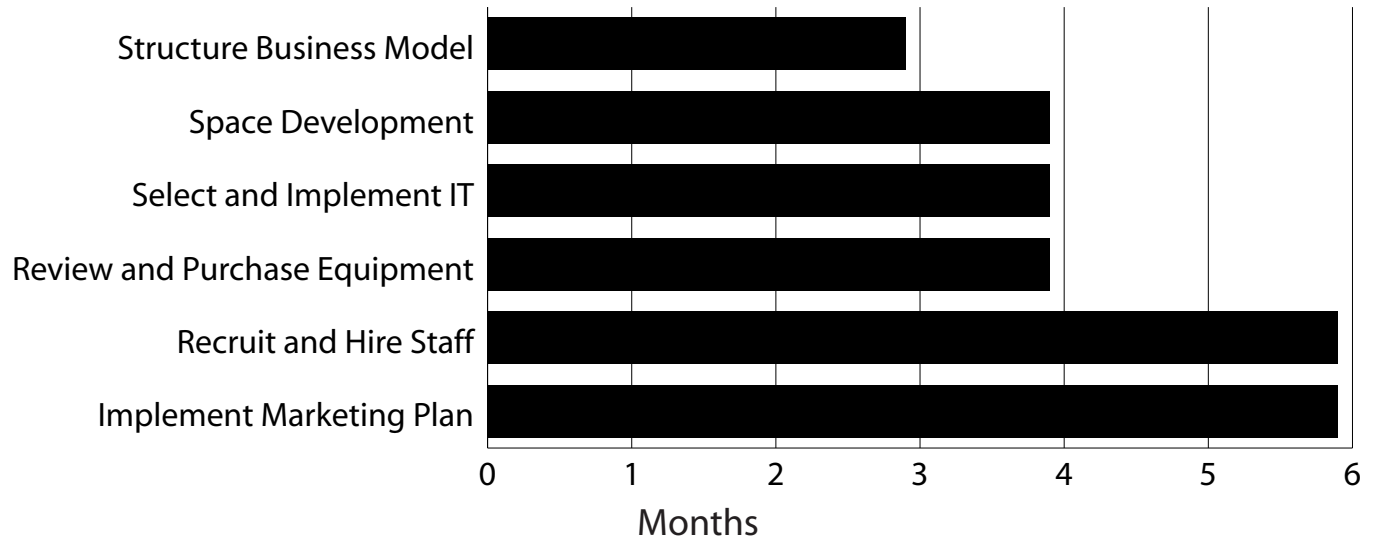

Fig 5. Milestones Chart

\section{Operational Considerations}

\section{Strategic Planning}

Business is critical to the development of a successful Pain Center. A market analysis, feasibility study and business plan should be developed to analyze the efficacy, both clinically and economically of the proposed Pain Center. This planning will serve as a blueprint for the Center as it relates to administrative, clinical, and economic issues. In addition, the development of the business plan allows all parties to project Center requirements based on the growth of the program, possible threats or competitive forces that may impact potential expansion of the Center and the resources required. Targeted marketing programs geared toward three segments of the market place must be implemented; high visibility marketing, public relations, and promotional activities are required to build volume and sustain growth over time.

Implementation is initiated by recruiting a multidisciplinary team, beginning with a core group of specialists. High profile, well-trained specialists help to create market domination in the geographic region for the Center. Physician and specialist integration is critical to map out clinical outcomes, recruit a management team, select an outcomes data collection system, and identify resources for public relations, marketing, and contracting (Fig. 5).

Clinical pathway algorithms coordinate diagnostic and therapeutic interventions, maximize clinical outcomes, improve return to work results, and document reduced cost of care.
Potential Structures of Ownership

There are many types of cooperative ventures available depending on the Pain Center location and its ownership. In some cases, the Center may represent a physician-owned spinal diagnostic and interventional pain ambulatory surgery center. In other instances, the interventional pain center may be part of a hospital facility or large academic institution. Many factors impact the Center's structure and physical location; free-standing, hospital-based, or institutional facility. It is important to analyze all the options including capital requirements for a bricks and mortar type center that focuses on outpatient care and procedures.

\section{Legal Issues}

Some types of joint ventures between physicians and hospitals have been found to violate the Federal Anti-Kickback Statute. This has occurred when distributions from the joint venture to the referral source are characterized as remuneration paid "in return for" or "to induce" referrals to the joint venture. A safe harbor provision is related to this statute however, in practice very few joint ventures will actually satisfy the safe harbor requirement. In particular, the first element of the safe harbor states that no more than $40 \%$ of the value of the investment interest of each class of investments may be held in the previous fiscal year or the previous 12 month period by investors who are in a position to make or influence referrals to, furnish items or services to, or otherwise generate business for the entity. It must be noted that just because the arrangement does not fall within the safe harbor, it does not necessarily make it illegal.

In addition, the Office of the Inspector General (OIG) issued a special fraud alert with respect to joint venture arrangements. Of the items that the OIG has identified as suspect, extraordinary returns on investment in comparison with the risk involved has been included. Further, certain Stark issues apply and the entity would need to fit within an exception of these requirements. To further complicate the issue, a number of states such as California are looking to pass legislation that prohibits the referral of work-related injury patients requiring musculoskeletal care to a physicianowned ambulatory surgery center. The battle to retain these referrals and market share is currently being launched on several fronts in key states with the help of organizations like The American Society of Interventional Pain Physicians (ASIPP) whose governmental affairs program has achieved major milestones on behalf of physicians and facilities providing pain services.

In some circumstances, the use of a general business corporation as a joint venture entity may be preferable where there is a tax-exempt participant, if the venture will generate income that is "unrelated" to the charitable purpose of the tax-exempt entity.

Pain Center as a Department of a Hospital

The advantage of this structure is that the hospital can fund and staff the 
program. The physician members are those physicians on staff who wish to participate and no physician financial contributions are required. This structure works well for a program that is established principally as a marketing tool. It may not work well however, for Pain Centers that want to develop treatment protocols and exclude physicians who do not choose to follow them.

\section{Pain Center as a Joint Venture}

Where physicians are willing to fund a proportionate share of the costs of a Pain Center, this structure provides greater control over membership and the quality of care. Under this structure, a limited liability corporation is formed between the hospital and the participating physicians. Both the hospital and the physicians share in the costs and the revenues directly attributable to the joint venture including staff costs and marketing. Capital purchases made on behalf of the hospital to support the services provided by the member physicians, if made available to other staff physicians, do not have to be jointly funded. In this structure, internal staffing is kept to a minimum to keep overhead low. Hospital marketing that includes the Pain Center as one of its many programs, can be hospital funded.

Pain Center as a Management Services Organization

This structure works well in a mature physician/hospital relationship where the hospital and the physician members of the Pain Center want to consolidate business functions. It allows the greatest reduction in duplicate paperwork by having the Management Services Organization (MSO) bill globally for both the professional and facility components. This model requires commitment by both the physicians and the hospital; services and revenues will be consolidated. Further, to remain within federal and state regulations governing physician/hospital business relationships, great care is required in the structure and operation of the Pain Center.

\section{Physical Space, Staff, and Equipment Requirements}

After the business plan has been developed, the next phase focuses on physical space, staffing, equipment, computer network, and communication structure requirements. Issues addressed dur- ing this phase include support staff organization, clinical and administrative data flow, management, and operations of the Pain Center. Creation of a seamless stream of data between physician offices and the Pain Center is particularly appealing to patients as their medical history, chief complaints, and prior treatments become part of one centralized record shared by the team. Patients supply this information once and it is made available to each provider. The integration of data and communication among team providers eliminates the perception of "fragmented" care and promotes improved overall medical management. Based on patient surveys, this feature alone is a key draw for the Pain Center. It conveys a strong sense of comprehensive, coordinated "patient" focused care.

\section{Implement Information Technology (IT)}

The communication infrastructure is paramount to the long-term success of the Pain Center and is a key marketing feature relative to patient satisfaction. Identifying the ideal operating software for the Pain Center includes point-of-care data collection, operations, billing, collections, scheduling, and clinical outcomes capabilities. The ability to interface with participating physicians' private practices, including porting and converting of databases to and from the practice will facilitate coordination of care and communication among those involved in the patient's treatment plan. Patients appreciate paperwork reduction and medical history repetition. To provide some measure of accountability to third-party payers and referral sources, outcomes data collection should be addressed early as a necessary component to measure the efficacy of the Pain Center and its team of providers.

As reported in the May 27, 2003 issue of The Wall Street Journal, the Centers for Medicare and Medicaid Services (CMS) has launched several new initiatives that reward both facilities and physicians who document high patient satisfaction in an overall outcomes data collection program. Some carriers, such as Blue Cross and Blue Shield, suggest that they will increase rates of reimbursement on the basis of physician report cards and high rates of patient satisfaction. Outcomes data collection is critical to the contracting and marketing process.

To distinguish the Pain Center, nationally established criteria for out- comes measurement can be established as benchmarks. When possible, independent collection of outcomes by a thirdparty is preferred to preserve the integrity and credibility of the data. Quarterly distribution of this information should be made available to key employers, insurance carriers, medical groups, and referrals sources.

Costs of a Center are illustrated in Table 1.

\section{MARKETING}

The practice of interventional pain management has changed substantially since the 1990s and evolved into a distinct specialty. Along with the understanding of interventional pain management, the evolution of numerous techniques also have changed in conjunction with practice and regulations of interventional pain management. Numerous hurdles for today's interventional pain management include decreasing reimbursement, increasing operational costs, and competition within and outside the specialty. Healthcare, once controlled by physicians and hospitals, is now driven by numerous forces, including government, payors, patients, and advocacy groups. Thus, it is now more important than ever that an interventional pain management practice or a spine care center market their services and establish proper relationships.

However, physicians must be cautious in developing marketing and public relationships. Numerous regulations governing marketing of physician practices must be followed. These include not only the regulations of government in relation to fraud and abuse, self-referrals, but also the regulations related to practice of medicine in each state.

\section{Develop a Marketing Plan}

A comprehensive marketing plan must be developed to include budgets, forecasts, return on investment projections, plan of execution, and related vendors. An administrator for the program should be selected and be responsible to implement all approved components of the marketing plan. This may include the recruitment of a Director of Marketing, if indicated, per established salary and commission guidelines.

\section{Market Position}

Quality differentiation among providers is difficult for health care consum- 
ers. As a result, marketing plays a significant role in the choices consumers make. A Pain Center allows services to be more effectively marketed both within primary and secondary service areas. Depending on the market domination of existing programs, the influx of industry, and increased population to the region, considerable resources may need to be invested in marketing and promotion of the Pain Center.

In geographic areas experiencing rapid growth, new residents may not have preconceived opinions about providers and are not yet tied into the local medical community. Therefore, marketing is especially important. A concise, consistent public image coupled with an awareness campaign that focuses on the skill set of the Pain Center's specialists, documented clinical outcomes, as well as cost savings will improve and influence public, medical, third-party payer, and employer utilization of the proposed Pain Center.

Proper market positioning can create "high profile" awareness and reduce clinical dilution of patient referrals from competitive forces in the area. The desired community perception is one that positions the Pain Center as a state-ofthe-art, comprehensive delivery system in a well-equipped, patient-friendly facility. Office and medical staff are trained to courteously convey this image when dealing with physicians, patients, and the community. By creating the proper internal processes, treatment at the Pain Center will be viewed by the patient as a seamless process.

To increase referrals and work-related injury cases from employers, adjusters and case managers; the program must be marketed through documented outcomes that demonstrate the cost effective, clinical and patient satisfaction benefits of the program.

\section{Marketing Methods}

After the marketing plan is complete, including budgets, analysis of market position, timetables, and specific chronology of promotional events, the following techniques can be used to build public, medical, and payer recognition and increase case volumes:

- Establish a communication program using print, radio, media, the Internet, seminars, newsletters, and a web site, to target four different markets for direct referrals to the Pain Center: (1)
Third-party payers, managed care organizations, work related injury carriers, employers, case managers, claims examiners, and third-party administrators; (2) Urgent care centers, rehabilitation facilities, primary care physicians, independent physician associations, medical clinics, providers, chiropractors, and occupational medicine physicians; (3) Patients and the general public; and, (4) Attorneys.

- Invest in staff, equipment, outcomes data collection, and technology to position the Pain Center as the market leader in spine and pain care for the entire region.

- Establish a web site with a chat room for patients, referring physicians, case managers, medical directors, risk managers, human resource personnel, and claims examiners to discuss issues relative to outcomes, new modalities, technology, and cost containment of nonoperative and operative spine care, including interventional pain management.

- Set up seminars for personal injury and work-related injury attorneys (defense, as well as applicant). Offer continuing education (CEs) credits for their participation and attendance.

\section{Third-Party Payers}

- Perform a retrospective study of inand out-patient services for musculoskeletal, chronic illness, and pain management ICD 9 diagnoses treated at the hospital over the last 12 months to identify potential leads for new business from referring physicians, case managers, attorneys, employers, thirdparty payers, chiropractors, and allied health providers.

- Analyze the contractual base, as well as the demographics, of existing referrals to the hospital to identify opportunities for promotion of the Pain Center.

- Develop targeted marketing campaigns geared toward regional carriers, Third-Party Administrators (TPAs), case management groups, employers, etc. with a high density of at-risk occupational groups whose employee population has a high incidence of musculoskeletal injuries.

- Conduct migration studies to determine forces and trends of referral patterns for the region for neurosurgical, orthopedic, and musculoskeletal ad- missions, and develop strategies to recover lost market share.

- Conduct a retrospective outcomes analysis on key spine and musculoskeletal procedures, such as laminectomy. Disseminate the results via a white paper to key payers, PCPs, employers, and case managers in the region. Highlight treatment protocols used to generate the outcomes. Set up a prospective outcomes data collection system by an independent third-party and provide aggregate data on a quarterly or bi-annual basis to key employers, payers, and contracted entities in the region. Provide this data on the web site as well.

- Set up regional on-site payer seminars and in-services with continuing education (CEs) credits for payers, risk managers, case managers, adjusters, claims examiners, TPAs, and managed care organizations on non-operative/ operative spine care. Host half-day seminars that feature demonstrations, didactic lectures, and patient testimonial panels.

- Identify patterns of referrals from third-party payers, urgent care centers, skilled nursing facilities, and employers for non-operative/operative spine care. Develop carve-outs to direct business to the Pain Center, at the time of, or immediately, post-injury.

- Host separate education/social events for payers, employers, physicians, and patients co-sponsored by the industry as kick-off activities for the Pain Center.

- Secure directed payer/employer contracts for non-operative/operative spine care based on three criteria: (1) Accountability and objective outcomes; (2) Cost of care; and, (3) Return to function/work.

- Target indemnity insurers, Health Management Organizations (HMOs), Preferred Provider Organizations (PPOs), and the Independent Physicians Association (IPAs) and establish sole source gatekeeper contracts for spine and pain care. Utilize outcomes data to demonstrate the economic benefits of referring patients directly to the Pain Center and its spine program. Highlight the diagnostic, clinical, and therapeutic benefits of the program, including the integrated delivery of non-operative/operative care. Use critical pathway tools, outcomes measures, and the recruitment of ancillary specialists to significantly increase con- 
tract opportunities with these groups.

- Set up quarterly Pain Center educational outreach programs, including web casts and newsletters to address state-of-the-art advances in research and treatment of spinal disorders for payers, case managers, adjusters, TPAs, employers, and medical directors of large managed care or employer organizations in the region.

\section{Governmental Agencies}

- Generate an outcomes study assessing length of stay, complications, and medication utilization for geriatric admissions for musculoskeletal care and orthopedic surgery treated at the hospital over the last 12 months and disseminate results to the local intermediaries for Medicare in the region.

- Based on a high ratio of permanent and transient elderly citizens living in the area, a white paper cost benefits analysis should be conducted for musculoskeletal high-risk disease states and chronically ill populations treated at the Pain Center, as opposed to competing facilities in the area. This information should be disseminated to appropriate thirdparty payers and physician groups.

\section{Employers}

- Initiate a regional awareness campaign focused on medium to large corporate self-insured employers and their risk managers, human resource personnel, and on-site medical staff. Set up on- and off-site educational programs featuring prevention, treatment modalities, and outcomes from nonoperative/operative spine care.

- Consider negotiating at-risk carve-out contracts for non-operative/operative spine care based on three criteria: (1) Accountability and objective outcomes; (2) Cost of care; and, (3) Return to function/work.

- Identify new employer, industry, and manufacturing groups entering the area as opportunities for contracting for pre-placement screenings.

- Expand programs highlighting ergonomic considerations for the reduction of work-site related injuries and integrating at-risk employees into existing rehab programs.

General Public

- Expand consumer education programs for sports, spine, and disease-relat- ed musculoskeletal injuries utilizing print, media, television, and Internet resources for awareness, dissemination of information, and market positioning.

- Establish quarterly seminars for the general public highlighting various topics in the treatment of acquired, traumatic, and sports related musculoskeletal and spine conditions.

- Implement satisfaction surveys for spine and pain patients treated at the Pain Center. Analyze results and distribute to press, public, and patients via the Pain Center web site and newsletter.

- Setup an "Ask the Spine Expert" chat room on the Pain Center's web site for questions from healthcare consumers. Set up a series of web casts on spine related topics and disseminate the schedule to the media for maximum exposure and utilization.

- Link to entities such as www.spineuniverse.com for patient education, dissemination of information on the services and providers of the Pain Center, and Internet marketing of the Pain Center.

\section{Physician Groups and Allied Health Providers}

No marketing tool is more effective than direct physician interface. Consider including a direct marketing commitment from each member physician as a requirement of participation in the Pain Center. This should be structured as a specific monthly commitment of time (such as one half-day per month) to do the following: (1) Conduct direct physician-to-physician marketing in both the primary and secondary service areas of the Pain Center to develop and maintain referral relationships; (2) Send out personal referral acknowledgement letters and reports within 24-48 hours of examination of a new patient; (3) Establish a regional Speaker's Bureau featuring the Pain Center's physicians and staff to secure speaking engagements with target medical, patient advocacy, elderly, and community groups; (4) Attend specialty medical, surgical, and nursing professional meetings; (5) Set up symposiums and continuing medical education (CME) workshops for primary care, occupational medicine, neurology, internal medicine, physical medicine, and rheumatology physicians, target medical groups, chiropractors, nurses, and al- lied health providers; (6) Identify regional urgent care centers, rehabilitation facilities, primary care physicians, independent physician associations, medical clinics, providers, chiropractors, and occupational medicine physicians, for a direct mail campaign highlighting the services of the Pain Center; and, (7) Send out a personal letter, Pain Center announcement, and brochure to existing and potential new referring physicians. Establish an ongoing survey of existing physician referral sources to include their opinions, likes, and dislikes of the care rendered to patients they directly referred to the Pain Center.

\section{ConCLUSION}

The prevalence of chronic spinal pain and its impact on the society are enormous. The structural basis for chronic spinal pain is established in the majority of the cases. Evidence-based analysis of effectiveness of diagnostic and therapeutic interventional techniques is established at least with moderate certainty for at least $50 \%$ of the procedures. Thus, appropriate development and operation of a spinal interventional pain center appears to be the most appropriate way to practice spinal medicine with interventional techniques in the new millennium. This manuscript has reviewed the rationale, medical conditions, business model, and planning requirements for a spinal diagnostic and interventional pain center, including marketing programs designed to maximize the success of the entity in any setting.
Author Affiliation:
Marcy T. Rogers, M.Ed.
President/CEO
Management Technology Resources
8910 University Center Lane
Suite 270
San Diego CA 92122
E-mail marcyrogers@mtr-apm.com

\section{REFERENCES}

1. Lawrence RC, Helmick CG, Arnett FC. Es timates of the prevalence of arthritis and selected musculoskeletal disorders in the United States. Arthritis Rheum 1998; 41: 778-799.

2. Walker BF. The prevalence of low back pain in Australian adults. A systematic review of the literature from 1966-1998. Asia Pac J Public Health 1999; 11:45-51.

3. Cassidy D, Carroll L, Cotê P: The Saskatchewan Health and Back Pain Survey. The prevalence of low back pain and related disability in Saskatchewan Adults. Spine 
1998; 23:1860-1867.

4. Leboeuf-Yde C, Lauritsen JM. The prevalence of low back pain in the literature. A structured review of 26 Nordic studies from 1954 to 1993. Spine 1995; 20:2112 2118.

5. Côté DC, Cassidy JD, Carroll L. The Saskatchewan Health and Back Pain Survey. The prevalence of neck pain and related disability in Saskatchewan adults. Spine 1998; 23:1689-1698.

6. Frederiksson K, Alfredsson L, Koster M et al. Risk factors for neck and upper limb disorders: Results from 24 years of follow up. Occup Environ Med 1999; 56:59-66.

7. Leclerc A, Niedhammer I, Landre MF et al. One-year predictive factors for various as pects of neck disorders. Spine 1999; 24: 1455-1462.

8. Linton SJ, Hellsing AL, Hallden K. A population-based study of spinal pain among 35 45 year old individuals. Spine 1998; 23: 1457-1463.

9. Manchikanti L, Staats PS, Singh V et al. Evidence-based practice guidelines for interventional techniques in the manage- ment of chronic spinal pain. Pain Physician 2003; 6:3-80.

10. McNeil J. Americans with disabilities, 1994-95. Washington DC: US Department of Commerce, Economics and Statistics Administration, Bureau of the Census, 1997. (Current populations reports; series P 70, No. 61).

11. California Workers' Compensation Institute Proceedings, June 2000. US Labor Department, US Department of Health and Human Resources, 2000.

12. Hough J. Estimating the health care utilization costs associated with people with disabilities: Data from the 1996 Medical Expenditure Panel Surgery (MEPS). Annual meeting of the Association for Health Services Research, Los Angeles, California, 2000.

13. Leigh JP, Markowitz S, Fahs M et al. Occupational injury and illness in the United States. Estimates of costs, morbidity, and mortality. Arch Intern Med 1997; 157:15571568.

14. CDC. Prevalence of disabilities and associated health conditions among adults United States, 1999. MMWR 2001; 50:120-
125.

15. Freedman VA, Martin LG, Schoeni RF. Recent trends in disability and functioning among older adults in the United States. JAMA 2002; 288:3137-3146.

16. de Lissovoy G, Brown RE, Halpern M et al. Cost-effectiveness of long-term intrathecal morphine therapy for pain associated with failed back surgery syndrome. Clin Ther 1997; 19:96-112.

17. Simmons J, Avant W, Demski J et al. Determining successful pain clinic treatment through validation of cost effectiveness. Spine 1988; 13:24-34.

18. Bell G, Kidd D, North R. Cost-effectiveness analysis of spinal cord stimulation in treatment of failed back surgery syndrome. I Pain Symp Manage 1997; 13:286-295.

19. Turk DC. Clinical effectiveness and cost-effectiveness of treatments for patients with chronic pain. Clin J Pain 2002; 18:355-365.

20. Bogduk N. In defense of radiofrequency neurotomy. Letter to the editor. Reg Anesth Pain Med 2002; 27:439-447.

21. Straus BN. Chronic pain of spinal origin. Spine 2002; 27:2614-2619. 
